\title{
Medical training remains a barrier to starting a family
}

Cite as: CMAJ 2021 May 25;193:E782-3. doi: 10.1503/cmaj.1095942

Posted on cmajnews.com on May 7, 2021

W omen in medicine wait much longer to have children than those pursuing other careers but close that gap quickly once their training is completed, according to a study in JAMA Internal Medicine.

The population-based cohort study followed 5238 physicians and 26640 other women in Ontario during their reproductive years between 1995 and 2018.

On average, physicians gave birth to their first child at age 32, five years later than other women. Almost all physicians in the study did not have children until after age 28 - one year later than the average age at which other women had their first child.

"We found the delay was very much tied to the timing of training," says Dr. Andrea Simpson, an obstetrician and gynecologist and co-author of the study. "Medical students, for example, almost universally didn't have pregnancies during medical school."

Researchers also found that the specialties women chose in postgraduate medical training impacted their likelihood of starting a family. At all ages, women in family medicine were more likely to have a child than those in other specialties. According to Simpson, there is a "generalized sense" in surgical specialties that childbirth should be delayed until after training, although obstetrics and gynecology tends to be more accepting.

However, the researchers were surprised to discover how quickly physicians caught up to other women after they were licensed.
Overall, physicians were just as likely to have children as other women, "it was just all staggered much later in their reproductive life," said Dr. Maria Cusimano, lead author of the study and an obstetrics and gynecology resident. By age 37 , the incidence of childbirth was similar for both physicians (62.7\%) and other women (62.1\%).

While it's encouraging news for women in medicine who fear they may miss out on motherhood entirely because of their careers, the study authors noted that delaying childbirth increases the risks of infertility and pregnancy complications.

And despite advocacy efforts to reduce barriers to medical trainees starting families, the researchers found that delays in childbearing among physicians

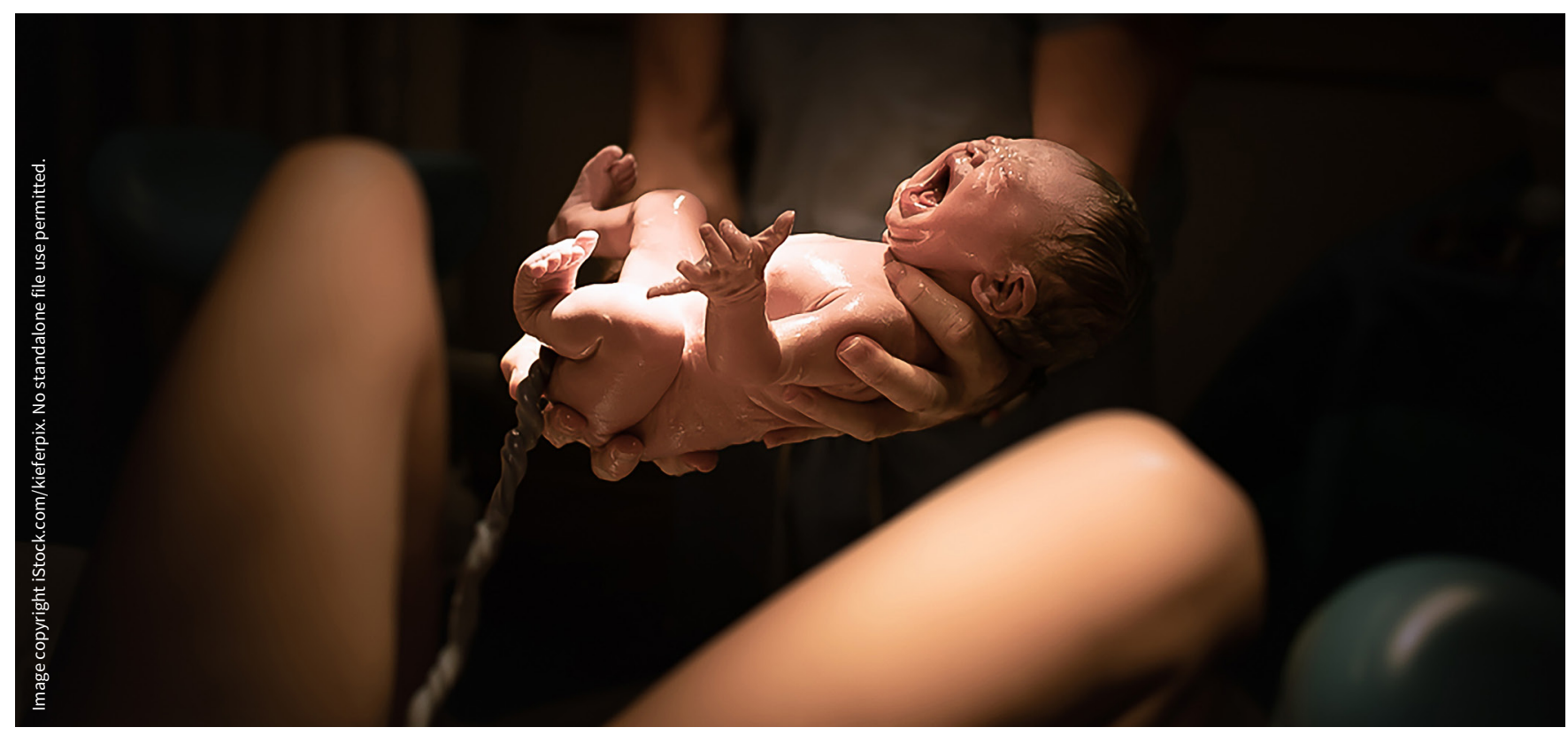

Women in medicine have children later than the general public, but eventually catch up after training. 
have not improved in recent years. "We thought that there might have been a shortening of that delay... as our culture has improved in medicine. But in fact, we saw the opposite," Cusimano said. The reasons for this trend are unclear but it may be related to longer medical training programs.

Cusimano and coauthors called for better supports for physicians and trainees starting families, including adequate parental leave, parental benefits, childcare that fits physicians' schedules, flexibility in undergraduate and postgraduate training schedules, and a culture of leadership that supports physician mothers.
"We still have work to do along the entire trajectory, from medical school to residency to staff, in terms of supporting physicians of any gender who want to become a parent," said Cusimano.

\section{Diana Duong, CMAJ}

Content licence: This is an Open Access article distributed in accordance with the terms of the Creative Commons Attribution (CC BY-NC-ND 4.0) licence, which permits use, distribution and reproduction in any medium, provided that the original publication is properly cited, the use is noncommercial (i.e., research or educational use), and no modifications or adaptations are made. See: https://creativecommons.org/ licenses/by-nc-nd/4.0/ 